\title{
Efficacy of Vitamin C Vaginal Tablets as Prophylaxis for Recurrent Bacterial Vaginosis: A Randomised, Double-Blind, Placebo-Controlled Clinical Trial
}

\author{
Vladislav N. Krasnopolsky ${ }^{\mathrm{a}}$, Vera N. Prilepskaya ${ }^{\mathrm{b}}$, Franco Polattic, Nina V. Zarochentseva ${ }^{\mathrm{a}}$, \\ Guldana R. Bayramova ${ }^{\mathrm{b}}$, Maurizio Caserini ${ }^{\mathrm{d}}$, Renata Palmieri ${ }^{\mathrm{d}, \mathrm{e}}$
}

\begin{abstract}
Background: The aetiology of bacterial vaginosis (BV) is still unclear but it is currently considered to be a synergistic polymicrobial syndrome. BV can often arise as a chronic or recurrent disease. The reason for such recurrences is not well elucidated. Previous studies have suggested that vaginal vitamin $\mathrm{C}$ may be a useful treatment in reducing recurrence rate, by increasing vaginal acidification and thereby making up for the decrease in hydrogen peroxide that results from a reduction in the number of lactobacilli present. Based on the above-mentioned consideration, a study was performed that aimed to evaluate the effect of vitamin $\mathrm{C}$ in the prophylaxis of $\mathrm{BV}$ relapses.
\end{abstract}

Methods: This was a randomised, double-blind, placebo-controlled, parallel-group clinical trial. One hundred and forty-two women, after having been cured from a recent episode of BV by either metronidazole or clindamycin, were randomised to receive vitamin C (74 patients) or placebo (68 patients) as prophylaxis for six monthly cycles, starting within 24 hours of the determination of 'BV cure'. The patients applied one vaginal tablet once a day for 6 consecutive days per month after menses.

Results: The rate of BV recurrence during the first 3 months was considerably lower in the vitamin $\mathrm{C}$ group $(6.8 \%)$ than in the placebo $(14.7 \%)$ group. Considering a 6 -month treatment period, the recurrence rate in the vitamin $\mathrm{C}$ group $(16.2 \%)$ was significantly lower $(\mathrm{P}=0.024)$ than in the placebo group $(32.4 \%)$. Moreover, at the same time point, the survival analysis of Kaplan Meyer was sig-

Manuscript accepted for publication June 10, 2013

${ }^{\mathrm{a}}$ Research Centre of Obstetrics and Gynaecology of Moscow Region, Moscow, Russia

${ }^{\mathrm{b}}$ Research Centre of Obstetrics, Gynaecology and Perinatology of Rosmedtechnologies, Moscow, Russia

"University of Pavia - "Medicine and Surgery" Faculty, Pavia, Italy

${ }^{\mathrm{d} S}$ Scientific Department, Polichem SA, Lugano, Switzerland

${ }^{\mathrm{e}}$ Corresponding author: Renata Palmieri, Via Senago 42/D, CH-6912

Lugano, Switzerland. Email: renata.palmieri@polichem.com

doi: http://dx.doi.org/10.4021/jocmr1489w nificant in favour of the vitamin $\mathrm{C}$ group compared with the placebo group $(\mathrm{P}=0.029)$.

Conclusions: The study showed that regular use of $250 \mathrm{mg}$ ascorbic acid vaginal tablets on 6 days per month for 6 months after successful treatment of bacterial vaginosis halves the risk of recurrence from $32.4 \%$ to $16.2 \%(\mathrm{P}=0.024)$.

Keywords: Bacterial vaginosis; Bacterial vaginosis prophylaxis; Vitamin C vaginal tablets; Ascorbic acid vaginal tablets

\section{Introduction}

Bacterial vaginosis (BV) is a common condition that affects almost one-third of women of childbearing age (29\%) [1]. In Caucasian women, the prevalence is $5 \%$ to $15 \%$; in African and black American women, it is $45 \%$ to $55 \%$; and in Asian women the prevalence is less well studied, but in general it is around $20 \%$ to $30 \%$ [2].

The aetiology of BV is still unclear but it is currently considered to be a synergistic polymicrobial syndrome, characterised by depletion of Lactobacillus spp and an intense increase (100- to 1,000-fold above normal levels) in vaginal anaerobic bacteria, including Gardnerella vaginalis, Prevotella spp, anaerobic gram-positive cocci, Mobiluncus spp, Mycoplasma hominis and Atopobium vaginalis [3, 4], leading to a replacement of lactobacilli and an increase in vaginal $\mathrm{pH}$.

$\mathrm{BV}$ can often arise as a chronic or recurrent disease and the reason for recurrences is not well known. Based on fluorescence in situ hybridisation of vaginal biopsy specimens, Mendling et al [4] have demonstrated that BV is associated with the development of an adherent polymicrobial biofilm that is highly organised and contains abundant Gardnerella vaginalis on the vaginal epithelium. Bacterial biofilms have recently been associated with several recalcitrant infections (involving Escherichia coli, Helicobacter pylori and Pseudomonas aeruginosa) [5]. The biofilm enhances bacterial attachment to epithelial surfaces, allows bacteria to reach much higher concentrations than in luminal fluids, and prevents the 
Table 1. Demographic and Baseline Characteristics in the Two Treatment Groups (Intention to Treat Population)

\begin{tabular}{|c|c|c|c|}
\hline Variable & $\begin{array}{l}\text { Vitamin C } \\
(n=74)\end{array}$ & $\begin{array}{l}\text { Placebo } \\
(n=68)\end{array}$ & $\begin{array}{l}\text { Total } \\
(n=142)\end{array}$ \\
\hline Demographic data & 74 & 68 & 142 \\
\hline Age (years) $($ mean $\pm \mathrm{SD})$ & $31.2 \pm 7.7$ & $31.0 \pm 7.2$ & $31.1 \pm 7.4$ \\
\hline Body weight $(\mathrm{kg})($ mean $\pm \mathrm{SD})$ & $61.0 \pm 9.4$ & $60.5 \pm 8.4$ & $60.8 \pm 8.9$ \\
\hline Height $(\mathrm{cm})($ mean $\pm \mathrm{SD})$ & $165.3 \pm 5.7$ & $165.9 \pm 6.2$ & $165.6 \pm 5.9$ \\
\hline Itching (mean $\pm \mathrm{SD}$ ) & $0.15 \pm 0.4$ & $0.16 \pm 0.37$ & $0.15 \pm 0.38$ \\
\hline Burning (mean $\pm \mathrm{SD})$ & $0.14 \pm 0.34$ & $0.13 \pm 0.38$ & $0.13 \pm 0.36$ \\
\hline Dysuria (mean $\pm \mathrm{SD})$ & $0.03 \pm 0.16$ & $0.04 \pm 0.21$ & $0.04 \pm 0.19$ \\
\hline Odour $($ mean $\pm \mathrm{SD})$ & $0.09 \pm 0.3$ & $0.19 \pm 0.43$ & $0.14 \pm 0.37$ \\
\hline Erythema (mean $\pm \mathrm{SD})$ & $0.01 \pm 0.12$ & $0.06 \pm 0.24$ & $0.04 \pm 0.19$ \\
\hline Oedema $($ mean $\pm \mathrm{SD})$ & $0.00 \pm 0.00$ & $0.03 \pm 0.17$ & $0.01 \pm 0.12$ \\
\hline Fissures (mean $\pm \mathrm{SD})$ & $0.00 \pm 0.00$ & $0.01 \pm 0.12$ & $0.01 \pm 0.08$ \\
\hline
\end{tabular}

drugs from reaching the bacteria, which reside in the film in a quiescent, latent state [6]. This observation might provide an explanation of the high rates of BV relapses [7, 8]. The presence of Atopobium vaginae strictly associated with Gardnerella vaginalis in the persistent and adherent bacterial biofilm has been confirmed [4], and seems to be the main reason for the failure of BV treatment [9]. Although some authors suggest that Atopobium vaginae may play a role in lowering the vaginal $\mathrm{pH}$ level through lactic acid production [10], Marconi et al have found that Atopobium vaginae content strongly increases if the vaginal $\mathrm{pH}$ is 4.9 or higher [11]. Therefore, they suggest that strains of this bacterium may have different capacities of lactic acid production but not to a significant level to safeguard the vaginal microflora.

Vaginal vitamin $\mathrm{C}$ is available as silicon-coated tablets containing $250 \mathrm{mg}$ ascorbic acid. This formulation is able to release the vitamin over hours, allowing a statistically significant vaginal $\mathrm{pH}$-lowering effect [12]. The efficacy of vaginal vitamin $\mathrm{C}$ in relieving $\mathrm{BV}$ signs and symptoms has been confirmed in two studies by Petersen et al $[13,14]$. Moreover, Abbaspour et al have showed that the efficacy of vaginal vitamin $\mathrm{C}$ in $\mathrm{BV}$ treatment is non-inferior to that of standard local metronidazole gel therapy [15].

The main goal of BV therapy and, in particular, of BV prevention is to keep the vaginal $\mathrm{pH}$ at 4.5 or lower, in order to prevent the overgrowth of pathogens until the normal lactobacilli are re-established and able to maintain the $\mathrm{pH}$ themselves [16]. Anaerobes grow poorly at $\mathrm{pH} 4.5$ or lower; the optimum $\mathrm{pH}$ for Prevotella spp and Gardnerella vaginalis growth is $6-7$. In vitro studies show that the concentrations of these bacteria increase with increasing $\mathrm{pH}$, but both are susceptible to low $\mathrm{pH}$. An ideal way to manage recurrent $\mathrm{BV}$ would be to maintain the vaginal $\mathrm{pH}$ at 4.5 with a prophylactic treatment that is able to control the overgrowth of bacteria. In this context, a viable therapeutic agent could be ascorbic acid, as it may able to help re-establish and maintain the vaginal ecosystem.

Based on the above-mentioned considerations, the present study aimed to evaluate the potential effect of vitamin $\mathrm{C}$, well known to have a vaginal $\mathrm{pH}$-lowering effect, in the prophylaxis of BV relapses in patients who have been cured from a BV episode.

\section{Materials and Methods}

\section{Ethics}

The study was fully Good Clinical Practice (GCP) compliant and was reviewed and approved by all relevant Independent Ethics Committees. All patients provided written informed consent prior to entering the study. 


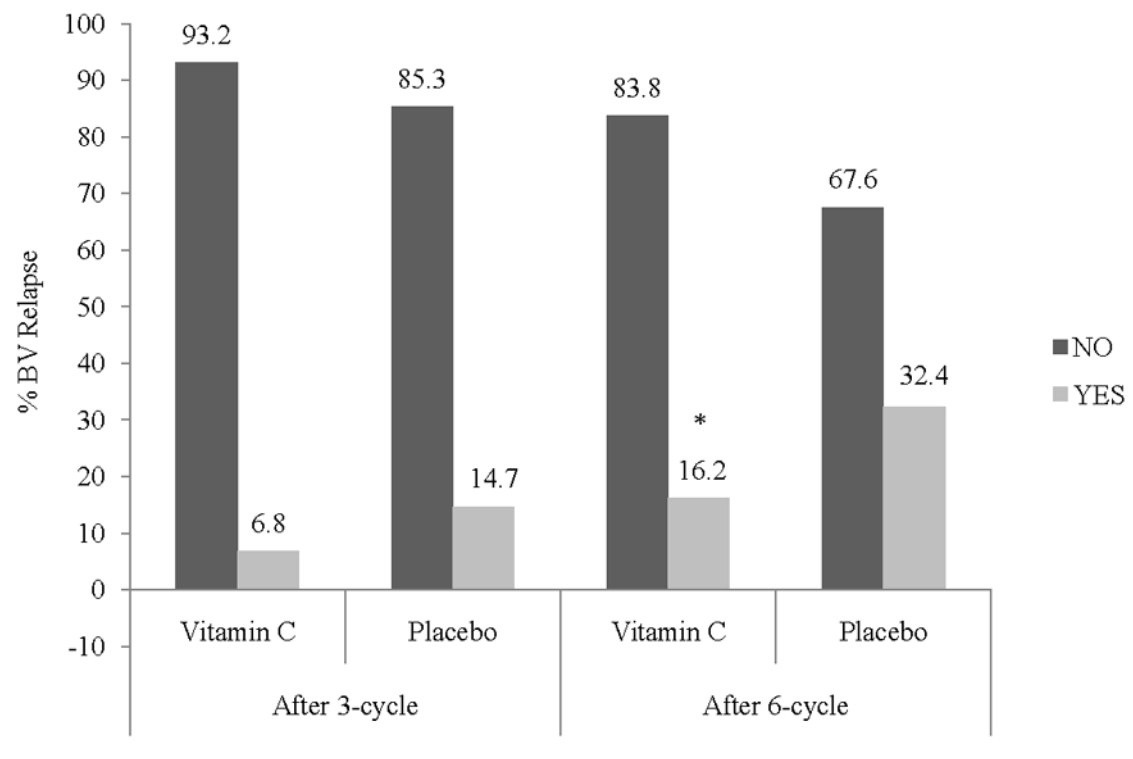

Vitamin C vs Placebo $=*$ p values $<0.05$ (Chi-square test)

Figure 1. Proportion of patients free of BV relapse after three-cycle and six-cycle periods of prophylaxis (Intention-to-treat population, $n=142$ ).

\section{Design and treatments}

This was a multicentre, randomised, double-blind, placebocontrolled, parallel-group clinical trial. The patient population, recruited in nine European sites located in Italy, Germany, Russia, Ukraine, Portugal and the Netherlands, consisted of 142 out-patient women, aged between 18 and 50 years, with history of recurrent episodes of BV defined as at least two acute episodes in the last 12 months. The BV diagnosis was based on the contemporary presence of at least three out of four Amsel criteria [17]: vaginal discharge, $\mathrm{pH}$ of vaginal fluid $>4.5$, amine (fishy) odour of vaginal discharge after addition of $10 \% \mathrm{KOH}$ (whiff test) and the presence of clue cells (>20\%) on microscopic examination.

Patients with diagnosis of human immunodeficiency virus (HIV) infection, gonorrhoea, Treponema pallidum, Herpes genitalis, trichomoniasis and/or candidiasis, or concomitantly treated with immunosuppressant, antibiotics, Lactobacillus preparations, acidifying agents, disinfectants, or vaginal douching were excluded.

Eligible women, cured (confirmed by the absence of three out of four Amsel criteria [17]) from an episode of BV by a course of either metronidazole or clindamycin, were randomly (1:1) assigned to receive $250 \mathrm{mg}$ ascorbic acid vaginal tablets or placebo as prophylaxis for six monthly cycles, starting within 24 hours from the determination of 'BV cure'. The patients applied one vaginal tablet once a day for 6 consecutive days per month after menses. The women were instructed to insert the tablets deep into the vagina at bedtime and were supplied with $250 \mathrm{mg}$ ascorbic acid tablets or matching placebo.

The overall prophylaxis was set by six cycles of applications but, when the first BV relapse occurred (confirmed by the presence of three out of four Amsel criteria [17]), the patients were discontinued from the study.

\section{Assessments}

Clinical visits were conducted at the end of each cycle, within 3 days of the end of the treatment, and 1 month after the end of the last cycle (final visit). The diagnosis of BV was documented by collecting two specimens of vaginal discharge: the first sample for microscopic examination (detection of clue cells) of the fresh smear and the second one for the whiff test. Moreover, BV signs and symptoms were recorded (itching, burning, dysuria, odour, erythema, oedema, and fissures) and scored by means of a four-point scale as follows: $0=$ absent, $1=$ mild, $2=$ moderate and $3=$ severe.

Vaginal $\mathrm{pH}$ measurements were performed by the patients themselves using a $\mathrm{pH}$-measuring device, namely pHem-Alert ${ }^{\circledR}$ (Gynex Corporation, USA) during each cycle: before and 12 hours after the first application, 12 hours after the last application and during the application-free period on days 10 and 15 .

The primary efficacy variable of the study was the time to the first BV relapse diagnosed according to Amsel criteria [17]. Secondary end-points were the evaluation of the $\mathrm{pH}-$ lowering effect of vitamin $\mathrm{C}$, the evaluation of the frequency 


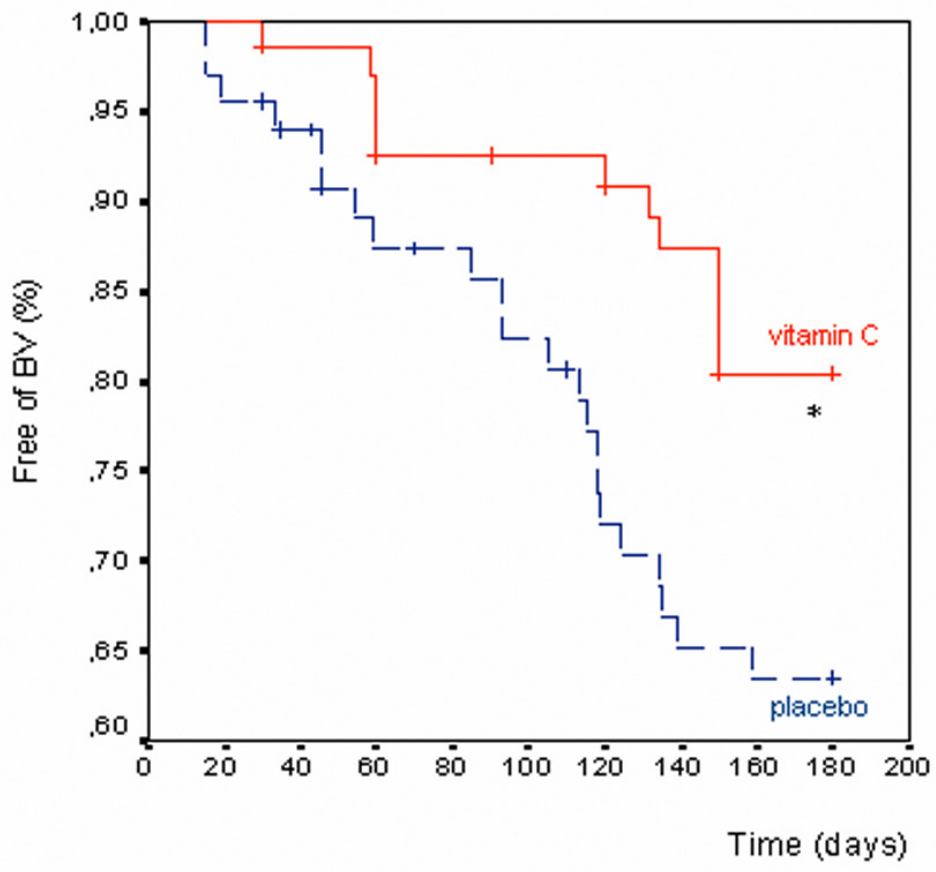

Vitamin C vs. placebo $=*_{p}$ values $<0.05$ (Log-rank test)

Figure 2. Kaplan-Meier survival analysis after six-cycle period of prophylaxis (Intention-to-treat population, $n=142$ ).

of BV sign and symptoms during the prophylaxis period, global assessment of the acceptability of the product by investigators and patients and the evaluation of the safety of vitamin $\mathrm{C}$. The acceptability and tolerability of the product were evaluated by the patient and the investigator, respectively, according to the following five-point scale: $1=$ very good, $2=$ good, $3=$ fair, $4=$ poor and $5=$ intolerance.

\section{Statistical analysis}

All randomised patients who fulfilled the inclusion/exclusion criteria and had received at least one dose of the study medication were included in the intention-to-treat (ITT) analysis. In case of premature discontinuation or missing data in completed patients, the last observation carried forward approach (LOCF) was used and the final available observation was considered as an end-point value. All enrolled patients were considered as the safety population. The sample size was determined based on the chi-square test and the power was $85 \%$ to detect an odds ratio (O.R.) of 0.26 .

The randomisation list was computer-generated in blocks of four with treatments balanced (1:1) within blocks, by the Biometry Department of Medi Service s.r.l., Italy, using the SAS Package 8.2, validated routine from the Computerized System Validation Process. Variables of an ordinate classification and dichotomous type were tested by the chi-square test according to the Mantel-Hanszel extension.
The proportion of subjects free of BV relapse after three or six cycles of prophylaxis was calculated considering the time from randomisation to the occurrence of the first event or to the last visit if the event did not occur. The event-free survival curve (EFS) was estimated according to KaplanMeier and the EFS in the two treatment groups were compared by means of the log-rank test.

The Cox regression model was adopted to evaluate the effects of the therapeutic regimen, adjusting for different confounding or prognostic factors and to evaluate the impact on prognosis of these factors. Both baseline and time-dependent covariates were considered in the multivariable model. The $\mathrm{pH}$-lowering effect and the vaginal signs and symptoms were analysed using the Mann-Whitney test for inter-treatment comparisons and the Friedman test for intra-treatment analysis. Investigators' and subjects' judgements on the acceptability of the product in the two treatment groups were compared using the Wilcoxon Rank Sum test.

All tests of hypotheses were performed using two-sided tests at a $5 \%$ significance level.

\section{Results}

\section{Patient population}

Overall, 142 women were randomised; 74 (52\%) received 

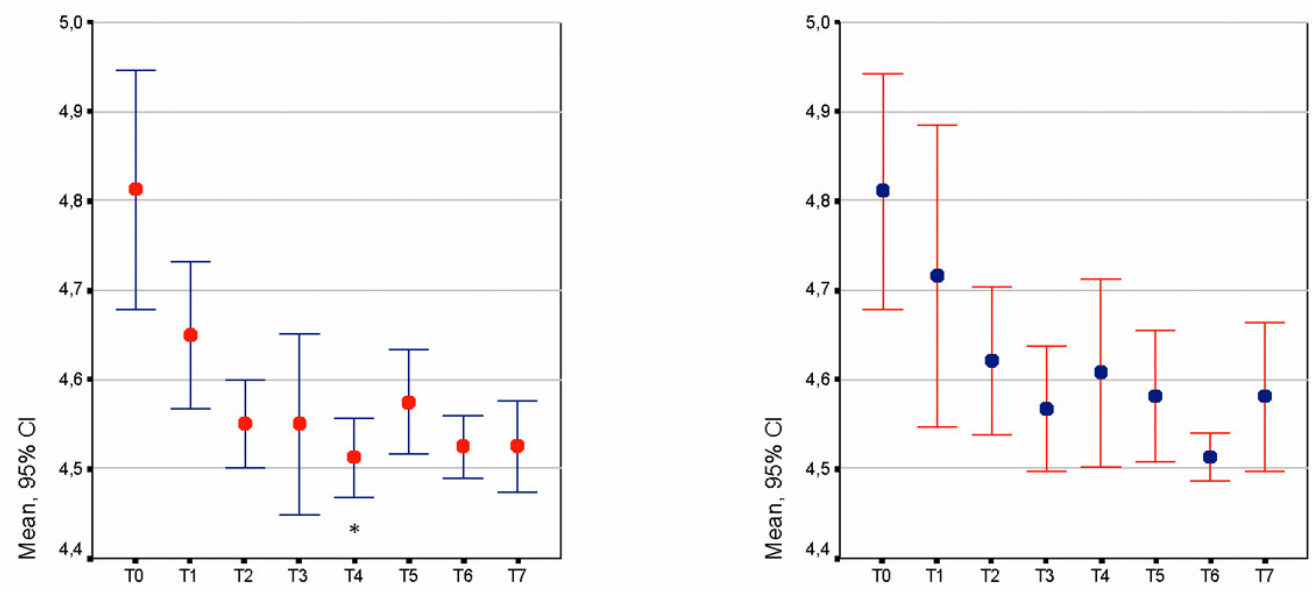

Vitamin C vs. placebo $=*$ p values $<0.05$ (Mann-Whitney test)

Figure 3. (a). Vaginal pH-lowering effect of vitamin $\mathrm{C}$; (b): Vaginal $\mathrm{pH}$-lowering effect of placebo.

ascorbic acid and the other 68 (48\%) received placebo. The two groups were homogeneous for age, height and weight distribution. BV signs and symptoms (itching, burning, dysuria, odour, erythema, oedema and fissures) were fairly similar across treatment groups, as summarised in Table 1.

\section{Proportion of patients free of $\mathrm{BV}$ relapses}

The proportion of women having a BV recurrence in the ITT population during the first 3 months was $6.8 \%$ in the vita$\min C$ group $(5 / 74)$ and $14.7 \%(10 / 68)$ in the placebo group, but the difference between the groups was not statistically significant. After 6 months of treatment, the recurrence rate was $16.2 \%$ in the vitamin $\mathrm{C}$ group compared with $32.4 \%$ in the placebo group (Fig. 1), which was statistically significant $(\mathrm{P}=0.024$, chi-square test). The results were confirmed by the O.R. that represents the risk of a recurrent episode of $\mathrm{BV}$ in the group treated with vitamin $\mathrm{C}$ in comparison to the placebo group. After six cycles of prophylaxis, the O.R. was $0.405(95 \%$ confidence interval $(\mathrm{CI})=0.182-0.901)$. The result was statistically significant since the $95 \%$ CI of the O.R. did not include the value ' 1 '.

The Kaplan-Meier survival analysis (Fig. 2), probability of being free of BV relapse in the two groups during the period of prophylaxis, became statistically significant starting from the 5 -month time point $(\mathrm{P}=0.039$ vitamin $\mathrm{C}$ vs. placebo, log-rank test); the significant difference was maintained and increased at the 6-month evaluation (end of treatment,

Table 2. Patients With at Least One AE (Safety Population)

\begin{tabular}{|c|c|c|}
\hline \multirow{2}{*}{ Adverse event } & \multicolumn{2}{|c|}{ Treatment group } \\
\hline & Vitamin $C(n=74)$ & Placebo $(n=68)$ \\
\hline Burning, itching, skin irritation & $3(4.0 \%)$ & $4(5.9 \%)$ \\
\hline Candidiasis & $1(1.4 \%)$ & $1(1.5 \%)$ \\
\hline Cystitis & - & $1(1.5 \%)$ \\
\hline Nausea & - & $1(1.5 \%)$ \\
\hline Bronchitis & $1(1.4 \%)$ & - \\
\hline Major depression & - & $1(1.5 \%)$ \\
\hline Flu & - & $1(1.5 \%)$ \\
\hline
\end{tabular}


$\mathrm{P}=0.029)$.

\section{Effect of prophylaxis on vaginal signs, symptoms and $\mathrm{pH}$}

BV signs and symptoms did not show any statistically significant differences through the treatment study period (from baseline to the follow-up visit), or in comparison of the treatment groups at the evaluated time points. The $\mathrm{pH}$-lowering effect of vitamin $\mathrm{C}$ was detected after a prophylaxis period of 3 months, with a reduction of $3.8 \%$ compared with the baseline value and becoming statistically significant compared with placebo (Fig. 3) after four cycles of treatments (P $=0.032$, Mann-Whitney test). The acceptability of treatment was judged as very good or good by $80.8 \%$ and $76.5 \%$ of investigators for the vitamin $\mathrm{C}$ and placebo groups, respectively, and by $76.7 \%$ of patients treated with vitamin $\mathrm{C}$ and by $75.0 \%$ of patients treated with placebo.

\section{Safety}

The safety of vitamin $\mathrm{C}$ treatment was similar to placebo. The most common treatment-related adverse events (AEs) in both groups were local reactions such as itching burning, and skin irritation ( $n=3$ in the vitamin C group; $n=4$ in the placebo group). All the AEs are showed in Table 2.

Local tolerability was judged as very good or good by $75.3 \%$ of patients and $86.0 \%$ of investigators after vitamin $\mathrm{C}$ treatment and by $76.6 \%$ of patients and $82.0 \%$ of investigators after placebo.

\section{Discussion}

A therapeutic approach in the treatment of BV relapse is to re-establish and maintain the physiological acidity of the vagina, as the growth of anaerobes and other faecal bacteria is inhibited by low $\mathrm{pH}$. Attempts to achieve this via re-colonisation with exogenous lactobacilli have not been successful. Another, more accepted approach is to reduce vaginal $\mathrm{pH}$, in order to create a negative environment for pathogen growth and to achieve long-lasting normalisation of vaginal flora using intravaginal ascorbic acid (vitamin C). The use of antibiotics may induce resistance in the pool of bacteria recognised to cause BV and, conversely, could affect the normal flora of lactobacilli [9], favouring recurrence within a few weeks in over $70 \%$ of women taking antibiotics for bacterial vaginosis [18]. Ascorbic acid $(250 \mathrm{mg}$, in a silicone carrier that ensures prolonged action) plays a vital role in maintaining low vaginal $\mathrm{pH}$ values and enhances healing processes in the vaginal ecosystem - recolonisation with lactic acid bacteria. The mechanism of action is simple: through the lowering of vaginal $\mathrm{pH}$ to the physiological level of $3.8-4.5$, anaerobic overgrowth is inhibited and the conditions for the re-growth of physiological lactobacilli flora are re-established.
The results of the present study show that $250 \mathrm{mg}$ ascorbic acid vaginal tablets taken 6 days per month safely halves the risk of BV recurrence from $32.4 \%$ to $16.2 \%$ during a 6-month prophylactic treatment. The O.R. confirms that subjects treated with placebo had a doubled risk of BV recurrence compared with the group of subjects treated with vitamin C. Considering the time to the first BV relapse, treatment of at least five cycles is necessary in order to reduce, at a significant level, the risk of BV recurrence. As this was a prophylaxis study, in women who at the screening visit were healthy and who terminated the study in case of relapse, a between-treatment difference in clinical parameters was not expected. At the same time, differences in $\mathrm{pH}$ were not expected but conversely, a reduction in $\mathrm{pH}$ was noted for 3-month and 6-month treatment.

In conclusion, regular use of silicon-coated vitamin $\mathrm{C}$ $(250 \mathrm{mg})$ tablets, after the standard antibiotic treatment for $\mathrm{BV}$, protects women by reducing the risk of recurrence probably by re-establishing the normal lactobacilli flora that is able to maintain vaginal $\mathrm{pH}$.

\section{Acknowledgement}

The contribution of the following persons to the investigation is gratefully acknowledged: Medi Service S.r.l., Agrate Brianza, Milan, Italy; R. Fasani and G. Reggiardo.

\section{Conflicts of Interest and Source of Funding}

Vladislav N. Krasnopolsky, Vera N. Prilepskaya, Franco Polatti, Nina V. Zarochentseva, and Guldana R. Bayramova received honoraria from Polichem S.A. as study investigators. Maurizio Caserini and Renata Palmieri are employees of Polichem S.A.

Polichem S.A. sponsored all phases of the study and supplied the trial product.

\section{Abbreviations}

AE: adverse event; BV: bacterial vaginosis; EFS: event-free survival curve; GCP: good clinical practice; HIV: human immunodeficiency virus; ITT: intention-to-treat population; LOCF: last observation carried forward; O.R.: odds ratio; SD: standard deviation.

\section{References}

1. Allsworth JE, Peipert JF. Prevalence of bacterial vaginosis: 2001-2004 National Health and Nutrition Examination Survey data. Obstet Gynecol. 2007;109(1):114-120. 
2. Donders G. Diagnosis and management of bacterial vaginosis and other types of abnormal vaginal bacterial flora: a review. Obstet Gynecol Surv. 2010;65(7):462473.

3. Sobel JD. Bacterial vaginosis. Annu Rev Med. 2000;51:349-356.

4. Swidsinski A, Mendling W, Loening-Baucke V, Ladhoff A, Swidsinski S, Hale LP, Lochs H. Adherent biofilms in bacterial vaginosis. Obstet Gynecol. 2005;106(5 Pt 1):1013-1023.

5. Tool GO, Kaplan HB, Kolter R. Biofilm formation as microbial development. Ann Rev Microbiol 2000; 54: 49-79.

6. Swidsinski A, Mendling W, Loening-Baucke V, Swidsinski S, Dorffel Y, Scholze J, Lochs H, et al. An adherent Gardnerella vaginalis biofilm persists on the vaginal epithelium after standard therapy with oral metronidazole. Am J Obstet Gynecol. 2008;198(1):97.e1-97.e6.

7. Hay P. Recurrent Bacterial Vaginosis. Curr Infect Dis Rep. 2000;2(6):506-512.

8. Polatti F. Bacterial vaginosis, Atopobium vaginae and nifuratel. Curr Clin Pharmacol. 2012;7(1):36-40.

9. Togni G, Battini V, Bulgheroni A, Mailland F, Caserini $\mathrm{M}$, Mendling $\mathrm{W}$. In vitro activity of nifuratel on vaginal bacteria: could it be a good candidate for the treatment of bacterial vaginosis? Antimicrob Agents Chemother. 2011;55(5):2490-2492.

10. Zhou X, Bent SJ, Schneider MG, Davis CC, Islam MR, Forney LJ. Characterization of vaginal microbial communities in adult healthy women using cultivation-independent methods. Microbiology. 2004;150(Pt 8):25652573.
11. Marconi C, Cruciani F, Vitali B, Donders GG. Correlation of Atopobium vaginae Amount With Bacterial Vaginosis Markers. J Low Genit Tract Dis. 2012;16(2):127132.

12. Polatti F, Rampino M, Magnani P, Mascarucci P. Vaginal $\mathrm{pH}$-lowering effect of locally applied vitamin $\mathrm{C}$ in subjects with high vaginal $\mathrm{pH}$. Gynecol Endocrinol. 2006;22(4):230-234.

13. Petersen EE, Magnani P. Efficacy and safety of vitamin C vaginal tablets in the treatment of non-specific vaginitis. A randomised, double blind, placebo-controlled study. Eur J Obstet Gynecol Reprod Biol. 2004;117(1):70-75.

14. Petersen EE, Genet M, Caserini M, Palmieri R. Efficacy of vitamin $C$ vaginal tablets in the treatment of bacterial vaginosis: a randomised, double blind, placebo controlled clinical trial. Arzneimittelforschung. 2011;61(4):260-265.

15. Abbaspour Z, Goodarzy F, Abbaspour MR. Comparison effect of vitamin $C$ vaginal tablet and metronidazole vaginal gel on treatment and relapse of bacterial vaginosis. Afr J Pharm Pharmacol 2010; 4: 484-489.

16. Wilson J. Managing recurrent bacterial vaginosis. Sex Transm Infect. 2004;80(1):8-11.

17. Amsel R, Totten PA, Spiegel CA, Chen KC, Eschenbach D, Holmes KK. Nonspecific vaginitis. Diagnostic criteria and microbial and epidemiologic associations. Am J Med. 1983;74(1):14-22.

18. Bradshaw CS, Morton AN, Hocking J, Garland SM, Morris MB, Moss LM, Horvath LB, et al. High recurrence rates of bacterial vaginosis over the course of 12 months after oral metronidazole therapy and factors associated with recurrence. J Infect Dis. 2006;193(11):1478-1486. 